\title{
Resolution of Metabolic Columns by a Double-Label 2-DG Technique: Interdigitation and Coincidence in Visual Cortical Areas of the Same Monkey
}

\author{
Harriet R. Friedman, Charles J. Bruce, and Patricia S. Goldman-Rakic \\ Section of Neuroanatomy, Yale University School of Medicine, New Haven, Connecticut 06510
}

\begin{abstract}
A double-label modification of the 2-deoxyglucose (DG) technique uses both ${ }^{3} \mathrm{H}-2-\mathrm{DG}$ and ${ }^{14} \mathrm{C}-2-\mathrm{DG}$ and allows for metabolic activity engaged by 2 distinct experimental conditions to be dissociated throughout the brain of a single subject. In the present study, we used this double-label method to examine the relationship between metabolic columns subserving the 2 eyes in cortical visual areas V1 and V2. The left and right eye's ocular dominance columns were separately activated in the same monkey to demonstrate that the double-label 2-DG method can resolve metabolic differences at the level of the cortical column. In 2 monkeys, ${ }^{14} \mathrm{C}-2-D G$ was injected first and one eye was occluded while the other eye was visually stimulated for $30 \mathrm{~min}$. Then ${ }^{3} \mathrm{H}-2$ DG was injected, and the occluder was switched so that the alternate eye was stimulated with the same pattern for 30 min. Autoradiographs depicting the 2 labels separately were obtained by exploiting the differential sensitivity of $X$-ray film and Ultrofilm to ${ }^{3} \mathrm{H}$ and ${ }^{14} \mathrm{C}$ emissions and by applying a radioactivity-subtraction algorithm to pairs of digitized images of the same section (Friedman et al., 1987).

Columnar regions of increased activity were evident throughout V1, excepting the representations of the optic disk and monocular crescent. Superimposition of the ${ }^{3} \mathrm{H}$ and ${ }^{14} \mathrm{C}$ images from the same sections demonstrated that columns of increased ${ }^{3} \mathrm{H}$ label were interdigitated with columns of increased ${ }^{14} \mathrm{C}$ label in V1. In contrast, bands of increased 3H-2-DG uptake in extrastriate area V2 were largely coincident with the bands of increased ${ }^{14} \mathrm{C}-2-\mathrm{DG}$ uptake. These results illustrate the value of the double-label 2-DG technique for studying fluctuations of metabolic activity under different experimental conditions in the same subject. In the present example, the demonstration that ocular dominance columns are interdigitated in V1, whereas metabolically active bands are coincident in V2, would not have been fully appreciated by comparing 2-DG labeling across separate animals.
\end{abstract}

\footnotetext{
Received Feb. 2, 1989; revised May 15, 1989; accepted May 23, 1989.

We are grateful for the expert assistance of JoAnn Coburn, Mary Pappy, Jamie Mazer, and Joseph Musco. The manuscript benefited from the critical reading of Dr. Pasko Rakic. This work was supported by USPHS grants MH08925 (H.R.F), EY04740 (C.J.B.), and MH38546 (P.S.G.-R.) and by a Jacob Javits Center for Neuroscience award NS22807.

Correspondence should be addressed to H. R. Friedman, Section of Neuroanatomy, Yale University School of Medicine, 333 Cedar Street, New Haven, CT 06510.

Copyright (C) 1989 Society for Neuroscience $0270-6474 / 89 / 124111-11 \$ 02.00 / 0$
}

The 2-deoxyglucose (2-DG) method (Sokoloff et al., 1977) for examining metabolic activity in the brain has found wide use in a variety of experimental studies with different animal species. Double-label modifications of the 2-DG technique increase its range of application by permitting 2-DG uptake to be mapped under 2 separate experimental conditions in the same animal (e.g., Altenau and Agranoff, 1978; Livingstone and Hubel, 1981; Friedman et al., 1987); however, autoradiograph images which reflect the activity of each label separately are difficult to obtain. We recently developed a digital subtraction method to separate the contribution of ${ }^{3} \mathrm{H}-2-\mathrm{DG}$ uptake from ${ }^{14} \mathrm{C}-2-\mathrm{DG}$ uptake in the same brain sections. This method was tested in a study wherein we administered ${ }^{14} \mathrm{C}$ - and then ${ }^{3} \mathrm{H}$-2-DG to rats while activating first one and then the other cortical hemisphere with unilateral sensory and electrical stimulation (Friedman et al., 1987). The images produced using the subtraction method showed hemispheric localization of ${ }^{14} \mathrm{C}$ - and ${ }^{3} \mathrm{H}-2$-DG uptake which accurately reflected the experimental conditions.

The double-label 2-DG method seems especially promising as a strategy for analysis of finer spatial fluctuations in brain activity, such as the columns which are considered by many to be a fundamental functional unit of cortical organization (e.g., Szentagothai, 1975; Mountcastle, 1978; Goldman-Rakic, 1984). In the present study, we tested the applicability of the method for studying columnar patterns of 2-DG uptake in the monkey's cerebral cortex. The primate visual system was selected for this analysis because of the well-documented columnar pattern of 2-DG uptake across the primary visual cortex (V1) that is produced by monocular visual stimulation in the macaque monkey (e.g., Kennedy et al., 1976; Hendrickson and Wilson, 1979; Horton and Hubel, 1981; Tootell et al., 1988a). In these previous studies using conventional 2-DG methods, the ocular dominance system could be labeled for only one eye in a given animal. With the double-label 2-DG method used in the present study, the ocular dominance patterns for both eyes can be simultaneously mapped in the same monkey. Consequently, we were able to directly examine the interrelationships of metabolic ocular dominance columns throughout V1 and the extrastriate areas as well. These data have appeared in preliminary form elsewhere (Bruce et al., 1985).

\section{Materials and Methods}

Two monkeys served as subjects in this experiment, a male Macaca mulatta (\#1, $4 \mathrm{~kg}$ ) and a female Macaca fascicularis $(\# 2,2 \mathrm{~kg})$. Both monkeys were adapted to the testing conditions for several weeks prior to the experiment. Opaque contoured ovals were used to occlude alternate eyes during the 2 viewing conditions. Monkey \#1 was seated in a primate chair and viewed images on a black-and-white television (RCA, 


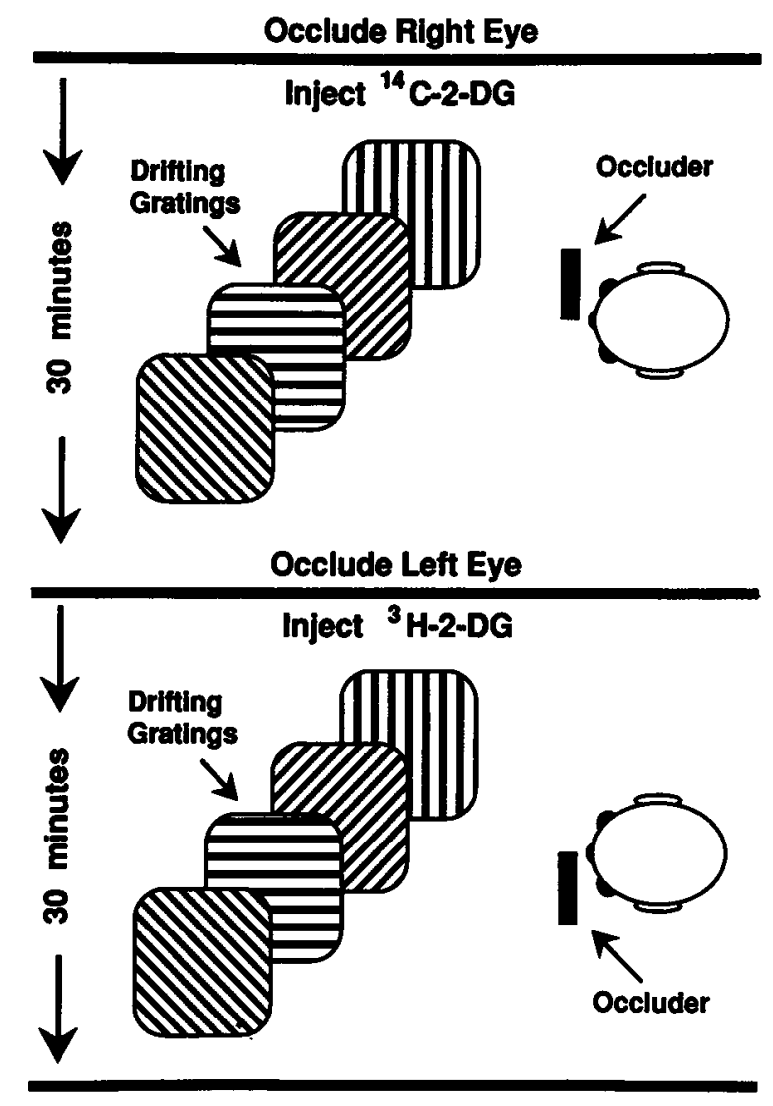

Overdose, Perfuse, Block, Freeze

Figure 1. Experimental time line for monkey \#2. The objective was to label the ocular dominance columns of the left eye with ${ }^{14} \mathrm{C}-2-\mathrm{DG}$ and then label the ocular dominance columns of the right eye with ${ }^{3} \mathrm{H}$ 2-DG. The procedure for monkey \#1 was very similar except that informal visual stimulation was used and there was no perfusion.

19 inch diagonal) in a darkened room during the experiment. These stimulation conditions are known to activate ocular dominance columns in striate cortex (Kennedy et al., 1976; Hendrickson and Wilson, 1979).

In monkey \#2, the experimental conditions were refined by fixing the head position of the monkey and by using computer-generated blackand-white contrast patterns as the visual stimuli. To hold the monkey's head during the experiment, a stainless steel headbolt assembly was implanted using aseptic surgical techniques and sodium pentobarbital anesthesia (i.v., to effect). For the 2-DG experiment, the monkey was seated in a primate chair facing a black-and-white video monitor (RCA, 19 inch diagonal); its head was fixed by the implanted headbolt, and the monitor screen was placed 12 inches from the eyes. Opaque contoured ovals again were used to occlude alternate eyes during the viewing conditions. This monkey viewed a square-wave grating pattern that drifted across the monitor's screen throughout the experiment. The orientation of the gratings was changed every $10 \mathrm{sec}$ in order to stimulate all cortical columns.

\section{Double-label 2-DG paradigm}

For both monkeys, ${ }^{14} \mathrm{C}-2-D \mathrm{D}$ was intravenously administered immediately prior to the first stimulation period. After $30 \mathrm{~min}$, the occluder was switched, and ${ }^{3} \mathrm{H}-2-\mathrm{DG}$ was intravenously administered; this was accomplished in 2-3 min. For monkey \#1, the right eye was stimulated during the ${ }^{14} \mathrm{C}-2-\mathrm{DG}$ period, and the left eye was stimulated during the ${ }^{3} \mathrm{H}-2-\mathrm{DG}$ period. For monkey \#2, the left eye was stimulated first $\left({ }^{14} \mathrm{C}\right.$ $2-D G)$ and the right eye was stimulated second $\left({ }^{3} \mathrm{H}-2-D G\right)$. Figure 1 illustrates the experimental paradigm for monkey $\# 2$.

The doses of 2-DG used were: $25 \mu \mathrm{Ci} / \mathrm{kg}{ }^{14} \mathrm{C}-2-\mathrm{DG}$ (New England Nuclear, $55 \mathrm{mCi} / \mathrm{mmol}$ ) and $2.5 \mathrm{mCi} / \mathrm{kg}{ }^{3} \mathrm{H}-2-\mathrm{DG}$ (New England $\mathrm{Nu}-$ clear, $30 \mathrm{Ci} / \mathrm{mmol})$. These doses are biased to favor ${ }^{3} \mathrm{H}(100: 1)$ in order to counterbalance the higher energy emissions of ${ }^{14} \mathrm{C}$ radioactivity in exposing film; however, they do not, in total molar volume of 2-DG, exceed the "trace" amount of the sugar prescribed by Sokoloff et al. (1977).

At the end of the second $30 \mathrm{~min}$ experimental period, the monkeys were killed by an overdose of sodium pentobarbital. In line with the protocol of Sokoloff and coworkers (Kennedy et al., 1976; Sokoloff et al., 1977), monkey \#1 was not perfused with fixative: its brain was rapidly removed and processed as described below. However, in the course of our studies (Friedman and Goldman-Rakic, 1988), we have found that the quality of the tissue is improved by perfusion (e.g., Collins, 1978), and therefore, monkey \#2 was perfused with $3.3 \%$ para-

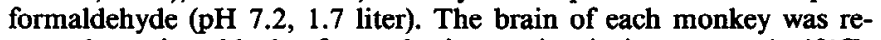
moved, cut into blocks, frozen by immersion in isopentane $\left(-40^{\circ} \mathrm{C}\right)$, and stored in a freezer $\left(-60^{\circ} \mathrm{C}\right)$ until sectioned on a cryostat. The occipital lobe was cut in the coronal plane on a cryostat $\left(-22^{\circ} \mathrm{C}\right)$ and tissue sections (20 $\mu \mathrm{m}$ thick) were saved on coverslips, rapidly dried on a hotplate, and apposed to film.

\section{Preparation of autoradiographs}

To obtain autoradiographs of ${ }^{14} \mathrm{C}-2-\mathrm{DG}$ uptake alone, all tissue sections were apposed to SB5 (Kodak) X-ray film with a Mylar sheet (Read Plastics, Rockville, MD) interposed for 45-50 d. The protective coating of the X-ray film together with the interposed Mylar blocks the exposure of this film by ${ }^{3} \mathrm{H}$ radiation while allowing exposure by the more energetic ${ }^{14} \mathrm{C}$ emissions (for example, see Friedman et al., 1987). These same sections were then apposed to Ultrofilm (LKB) for 15-18 d. This film is sensitive to both ${ }^{3} \mathrm{H}$ and ${ }^{14} \mathrm{C}$ radiation. A set of 10 plastic ${ }^{14} \mathrm{C}$ microscale standards (Amersham, ${ }^{14} \mathrm{C}$ tissue equivalence $=0-1.075 \mathrm{nCi} /$ $\mathrm{mg}$ ) was apposed to both types of film along with the tissue sections. Films were developed using GBX (Kodak) developer and fixative according to packaged instructions.

\section{Production of ${ }^{14} \mathrm{C}$ and ${ }^{3} \mathrm{H}$ images}

As we previously verified, autoradiographs produced on $\mathrm{X}$-ray film provide an accurate image of ${ }^{14} \mathrm{C}-2-\mathrm{DG}$ uptake because the protective coating of the X-ray film, together with the interposed Mylar sheet, effectively blocks nearly all of the weaker ${ }^{3} \mathrm{H}$ beta emissions. However, the Ultrofilm image reflects both ${ }^{3} \mathrm{H}$ and ${ }^{14} \mathrm{C}$ radioactivity, and therefore, the ${ }^{14} \mathrm{C}$ contamination must be removed to obtain an accurate image of ${ }^{3} \mathrm{H}-2-D G$ uptake. To implement this removal, $\mathrm{X}$-ray and Ultrofilm autoradiographs from the same tissue section were digitized using an image-analysis system comprised of a PDP 11/73 computer equipped with a graphics board (Datacube QVG-123, $768 \times 512$ pixels, 256 gray levels), a video camera (Dage MCI), a light box (SD Industries), and a color monitor (Hitachi, 19 inch diagonal). These digitized pairs of images were precisely aligned using an iterative algorithm which maximizes cross-correlations between selected contours in pairs of images, and both images were then converted to radioactivity levels via piecewise linear interpolation based on the ${ }^{14} \mathrm{C}$ standards coexposed on each film. Finally, the contaminating ${ }^{14} \mathrm{C}$ label, as quantified from the $\mathrm{X}$-ray image, was subtracted, pixel by pixel, from the ${ }^{3} \mathrm{H} /{ }^{14} \mathrm{C}$ composite Ultrofilm image. This procedure yields a quantitatively correct image of ${ }^{3} \mathrm{H}-2-\mathrm{DG}$ uptake (for more details, see Friedman et al., 1987).

Thus, 3 types of digitized images were obtained for each tissue section: (1) a direct visualization of the $\mathrm{X}$-ray autoradiograph showing ${ }^{14} \mathrm{C}-2$ DG uptake; (2) a direct visualization of the LKB autoradiograph showing both the ${ }^{14} \mathrm{C}$ and the ${ }^{3} \mathrm{H}$ label; and (3) a computed image of ${ }^{3} \mathrm{H}-2$ DG uptake produced by the subtraction algorithm. Photomicrographs of the computed ${ }^{3} \mathrm{H}$ image and the ${ }^{14} \mathrm{C}$ image were taken directly off the video monitor using a graphic recorder system (Matrix Instruments).

\section{Methods for comparisons of ${ }^{3} \mathrm{H}$ and ${ }^{14} \mathrm{C}$ images}

The double-label 2-DG technique yields 2 separate images that can be qualitatively compared. However, differences between these images, particularly when each shows a similar repetitive pattern, cannot be accurately resolved simply by making visual comparisons. Therefore, several protocols were developed to objectively compare the patterns and magnitude of 2-DG uptake $\left({ }^{3} \mathrm{H}\right.$ vs. ${ }^{14} \mathrm{C}$ uptake) across the 2 conditions. First, a dual-color mapping scheme was implemented to provide an overall view of the ${ }^{14} \mathrm{C}$ pattern in each image superimposed upon the pattern of ${ }^{3} \mathrm{H}-2-D G$ uptake of the same section. In this scheme, the ${ }^{3} \mathrm{H}$ label is represented by the color green and the intensity of this label is mapped as the intensity of the color. Similarly, the ${ }^{14} \mathrm{C}$ label is rep- 
resented by the intensity of the color red. In the images mapped in this way, nonoverlapping zones of increased activity appear as alternating red and green patches and coincident zones of increased activity appear as yellow. Exposure of tissue labeled by both ${ }^{14} \mathrm{C}$ and ${ }^{3} \mathrm{H}$ on color film can be also be used to yield qualitatively similar images because of the differential penetration of the emissions of the 2 isotopes through the 3 layers of color-sensitive emulsions, with ${ }^{14} \mathrm{C}$ producing a degraded red and ${ }^{3} \mathrm{H}$ producing yellow on color negative film (Kronenberg, 1979; Tootell et al., 1988c).

In addition, we quantitatively analyzed the columnar and other patterns of metabolic activity in the visual cortex by designating a series of points (splines) along the cortical layer showing the highest label density. A manual cursor was used to define these splines on the blackand-white digitized images of each brain section. The computer then used the spline series to construct a smooth tangential curve through the cortical region of interest, using the B-spline function (Newman and Sproull, 1973, pp. 320-324). The average label density at each point along the curve was then computed by averaging a given radial distance above and below the curve; the resulting set of $x, y, z$ triplets defined a "columnar density curve." The columnar patterns of 2-DG uptake that were measured generally extended through multiple cortical layers; therefore, the upper and lower radial distances for averaging were usually set to include laminae III and V, respectively. These averaged data were automatically adjusted via linear regression to correct for gradual density fluctuations across an image largely produced by the camera's optics and/or the lightbox (e.g., McCasland and Woolsey, 1988).

Because the identical series of splines are used to acquire columnar density curves for the aligned ${ }^{3} \mathrm{H}$ and ${ }^{14} \mathrm{C}$ images of each brain section, direct comparison of fluctuations in metabolic activity can be made using these pairs of curves in the following ways.

1. Density-strip plots. Columnar density curves were computationally straightened and their $z$ values were plotted as a row of adjacent vertical gray bars. Placing the ${ }^{3} \mathrm{H}$ and ${ }^{14} \mathrm{C}$ density-strip plots one above the other allows direct visual comparison of the ${ }^{3} \mathrm{H}$ and ${ }^{14} \mathrm{C}$ activity across a given segment of cortex. Furthermore, consecutive density-strip plots for a label can be stacked in order to reconstruct 2-dimensional maps of cortical metabolic activity for each condition (not shown).

2. Density graphs. Pairs of columnar density curves were graphed, using distance along the curve as the abscissa, activity level as the ordinate, and dotted/solid lines to distinguish one label from the other.

3. Across-label correlations. Pearson product-moment correlations between the 2 columnar density curves collected from the ${ }^{3} \mathrm{H}$ and ${ }^{14} \mathrm{C}$ images of identical brain sections were computed across the entire curve length or portions thereof. Positive correlations were indicative of coincident patterns of density fluctuation, whereas negative correlations indicated interdigitated patterns.

\section{Results}

\section{Ocular dominance columns in VI}

The ${ }^{14} \mathrm{C}$ images and the derived ${ }^{3} \mathrm{H}-2-\mathrm{DG}$ images both showed a columnar pattern of activity in the calcarine sulcus and dorsolateral surface of V1 (e.g., Fig. 2). This pattern indicated that the stimulation conditions we employed activated ocular dominance columns in both monkeys, although the columns from monkey \#2, who viewed high-contrast gratings and was perfused, were more distinct. As in the original demonstration of ocular dominance columns using the 2-DG method by Kennedy et al. (1976), these columns of high metabolic activity in both the ${ }^{3} \mathrm{H}$ and ${ }^{14} \mathrm{C}$ images were oriented perpendicular to the cortical surface and appeared to extend the full width of the cortex, being most pronounced in the middle laminae.

Although the ${ }^{3} \mathrm{H}$ and the ${ }^{14} \mathrm{C}$ images of V1 had a similar overall pattern of columnar activation, the analytical procedures outlined in Materials and Methods all showed that the sets of columns in these 2 images were not the same, but instead were interdigitated with each other. The pattern of interdigitating ${ }^{3} \mathrm{H}$ and ${ }^{14} \mathrm{C}$-labeled columns in V1 was most apparent in that portion lying along the dorsolateral surface of the occipital lobe. This is shown in the dual color images of Figure 2 (left side); a columnar pattern of activity is evident in the separate images of ${ }^{3} \mathrm{H}$ (green, middle left) and ${ }^{14} \mathrm{C}$ activity (red, top left), but the composite image (bottom left) shows that these red and green areas represent alternating zones of increased activity. The interdigitation of ${ }^{3} \mathrm{H}$ and ${ }^{14} \mathrm{C}$ columns also is graphically shown in Figures 3 (top) and 4 (top) for columnar density curves drawn across the dorsolateral surface of V1 in both monkeys. The peaks (columns of high activity) of ${ }^{3} \mathrm{H}$ label alternate regularly with those of ${ }^{14} \mathrm{C}$. This also is indicated by the oscillating dark and light areas in the density plots (shown above the graphs) and in the negative correlation coefficient obtained $(-0.42$ for monkey $\# 1$ and -0.46 for monkey \#2) for the ${ }^{3} \mathrm{H}$ and ${ }^{14} \mathrm{C}$ density curves taken from these brain sections.

To further examine the ${ }^{3} \mathrm{H}$ - and ${ }^{14} \mathrm{C}$-labeled ocular dominance columns, columnar density curves across the dorsolateral surface of V1 were generated for 11 successive sections (400 $\mu \mathrm{m}$ apart) spanning $4.4 \mathrm{~mm}$ of occipital cortex in both hemispheres of monkey \#2. The width of pairs of ${ }^{3} \mathrm{H}$ - and ${ }^{14} \mathrm{C}-2-\mathrm{DG}$ columns (hypercolumns) was measured over $10 \mathrm{~mm}$ of each contour curve of the 11 sections, starting from the dorsomedial edge (as shown in the spline curve of Fig. 3, top), and correlation coefficients were generated for each curve to assess the interdigitation of the individual ${ }^{3} \mathrm{H}$ - and ${ }^{14} \mathrm{C}$-labeled ocular dominance columns. The mean width of a ${ }^{3} \mathrm{H}-,{ }^{14} \mathrm{C}$-labeled hypercolumn was similar in both hemispheres (250 were measured overall), being $835 \mu \mathrm{m}( \pm 29 \mu \mathrm{m}, \mathrm{SEM})$ and $856 \mu \mathrm{m}( \pm 23 \mu \mathrm{m}, \mathrm{SEM})$ for the right and left hemispheres, respectively. The correlation coefficients obtained for the sections examined were all negative, again indicating that the ${ }^{3} \mathrm{H}$ and ${ }^{14} \mathrm{C}$ columns were largely interdigitated. The mean correlation coefficients for the right and left occipital cortex through the $4.4 \mathrm{~mm}$ sample area were -0.51 $( \pm 0.02, S E M)$ and $-0.47( \pm 0.03, S E M)$, respectively.

The pattern of interdigitating ${ }^{3} \mathrm{H}$ - and ${ }^{14} \mathrm{C}$-labeled columns was sometimes degraded in the region of the foveal representation near the external calcarine sulcus (not shown). This was evidenced by the more variable and less negative correlation coefficients between ${ }^{3} \mathrm{H}$ and ${ }^{14} \mathrm{C}$ columnar density curves taken from this region in monkey \#2. For example, for a sample of 4 sections in the right hemisphere (spanning $1.6 \mathrm{~mm}$ ), a mean correlation coefficient of $-0.03( \pm 0.10$, SEM) was obtained between columnar density curves that extended from the external calcarine sulcus to the V1/V2 border on the ventrolateral surface of the occipital lobe.

\section{Acolumnar regions of $\mathrm{VI}$}

The double-label 2-DG method also was sensitive to other aspects of visual cortex functional architecture. Thus, the monocular crescent and the optic disk representation were identified both because they were acolumnar and also because 2-DG uptake in these regions was labeled predominantly by only 1 of the 2 isotopes (e.g., see Kennedy et al., 1976). Figure 5 shows superimposed graphs of ${ }^{3} \mathrm{H}$ and ${ }^{14} \mathrm{C}$ activity for density curves across the dorsal bank of the calcarine sulcus for one section each of the right and left hemispheres in monkey \#2. The central area of the curve in which columnar activity is absent contrasts with the interdigitation of ${ }^{3} \mathrm{H}$ and ${ }^{14} \mathrm{C}$ ocular dominance columns at either end of the graph. The relative magnitude of the 2 labels in these acolumnar regions is consistent with the presence of the optic disk: the presumed optic disk representation in the left hemisphere (Fig. 5, top) is labeled with ${ }^{14} \mathrm{C}$, which is predictable given that ${ }^{14} \mathrm{C}-2-\mathrm{DG}$ was administered prior to $30 \mathrm{~min}$ of viewing with the left eye, and the temporal retina of the left eye provides the only innervation of the right hemifield optic 
disk representation. Conversely, in the calcarine cortex of the right hemisphere (Fig. 5, bottom), the superimposed ${ }^{3} \mathrm{H}$ and ${ }^{14} \mathrm{C}$ density graphs show the opposite effect with ${ }^{3} \mathrm{H}$ labeling the putative area of the optic disk representation. In general agreement with Kennedy et al. (1976), the optic disk representation occupied 2.5-5.5 mm across the calcarine sulcus in coronal sections and extended for about $2 \mathrm{~mm}$ (anterior-posterior).

More anteriorly within the calcarine sulcus the pattern of ${ }^{3} \mathrm{H}$ and of ${ }^{14} \mathrm{C}$ activity was again acolumnar (not shown); presumably this area represents the monocular crescent which receives visual inputs from the nasal retina of the contralateral eye (e.g., Kennedy et al., 1976). Thus, this region of the left cortex was labeled predominantly with ${ }^{3} \mathrm{H}$ because the contralateral eye was open during the administration of ${ }^{3} \mathrm{H}-2-\mathrm{DG}$ and occluded during the administration of ${ }^{14} \mathrm{C}$-2-DG. Conversely, the ${ }^{14} \mathrm{C}$ label predominated in the monocular crescent of the right hemisphere as the left eye was open when ${ }^{14} \mathrm{C}-2-\mathrm{DG}$ was injected.

\section{Patterns of 2-DG uptake in V2}

In both monkeys, zones of increased label density separated by regions of diminished label density also were evident in the ${ }^{3} \mathrm{H}$ and the ${ }^{14} \mathrm{C}$ images of occipital cortex lying outside of V1. Patchlike patterns of 2-DG uptake in extrastriate cortex have been noted previously (e.g., Humphrey and Hendrickson, 1983; Tootell et al., 1983; Crawford, 1985). For our report, analysis of extrastriate cortex has been confined to area V2, as judged by comparing our coronal autoradiographs with coronal sections showing physiologically mapped V2 (Gatass et al., 1981). As in $\mathrm{V} 1$, there were columnar bands of increased label density in V2 which extended from the white matter to the pial surface. However, in striking contrast to the interdigitated ocular dominance columns of $\mathrm{V} 1$, the bands of increased ${ }^{3} \mathrm{H}-2-\mathrm{DG}$ uptake in V2 largely coincided with the bands of increased ${ }^{14} \mathrm{C}-2-\mathrm{DG}$ uptake there. This is shown in the dual color images of Figure 2 (right side): bands of increased activity across $\mathrm{V} 2$ are evident in the separate images of ${ }^{14} \mathrm{C}$ (red, top right) and ${ }^{3} \mathrm{H}$ activity (green, middle right) but appear as yellow bands in the composite image (bottom right), showing that the areas of high activity labeled by ${ }^{3} \mathrm{H}$ and by ${ }^{14} \mathrm{C}$ largely overlap. In Figures 3 (bottom ) and 4 (bottom), superimposition of the ${ }^{3} \mathrm{H}$ and ${ }^{14} \mathrm{C}$ density graphs of columnar density curves taken from $\mathrm{V} 2$ in both monkeys again show that the bands of high activity for one label are aligned with the bands of high activity for the other label. Similarly, the 2 density strips through V2 show coincident bands of high and low label uptake (bottom of Fig. 3 and 4, above the graphs). Whereas these patterns were not always in perfect correspon- dence, the positive correlation coefficients which were obtained from these density curves, +0.66 and +0.54 (for Figs. 3 and 4, respectively), emphasizes the alignment of ${ }^{3} \mathrm{H}$ - and ${ }^{14} \mathrm{C}$-labeled bands of high metabolic activity in V2.

Overlapping bands of increased ${ }^{3} \mathrm{H}$ and ${ }^{14} \mathrm{C}$ activity were evident throughout V2. Columnar density curves were plotted for $10 \mathrm{~mm}$ segments of ventral V2 in 10 successive sections (400 $\mu \mathrm{m}$ apart) across a $4 \mathrm{~mm}$ anterior-posterior span in both hemispheres of monkey \#2. The mean correlation coefficients for the V2 density curves were $+0.59( \pm 0.03, \mathrm{SEM})$ and $+0.60( \pm 0.05$, SEM) for the right and left hemispheres, respectively. The periodicity of this $\mathrm{V} 2$ banding pattern also was examined. In the ventral, posterior portions of V2, the banding pattern was irregular; the width of the bands of high activity varied, and they alternated with regions of attenuated activity that were considerably larger than the bands themselves. Band widths across the $4 \mathrm{~mm}$ sample area ranged from $<500 \mu \mathrm{m}$ to $>2 \mathrm{~mm}$; however, most bands were between $1.0-1.5 \mathrm{~mm}$ wide, and the mean band width was $1.26 \mathrm{~mm}( \pm 0.06$, SEM, $n=80$ pairs). The widths of the interband segments of lower metabolic activity also was quite varied; the mean width was $2.06 \mathrm{~mm}( \pm 0.11, \mathrm{SEM})$, but widths ranged from 1 to over $3 \mathrm{~mm}$.

Interestingly, the pattern of 2-DG bands of high activity in $\mathrm{V} 2$ of both monkeys appeared to be more dense in the portion of V2 located in the dorsal bank of the lunate sulcus that represents central regions of the visual field (Gatass et al., 1981). In monkey \#2, the 2-DG bands at the level of the lunate sulcus were measured through 4 sections (spanning $1.6 \mathrm{~mm}$ ) from both hemispheres. In this $\mathrm{V} 2$ sample area, the mean band width was $970 \mu \mathrm{m}( \pm 50, \mathrm{SEM})$, and the mean width of interband segments was $1.85 \mathrm{~mm}( \pm 1.13 \mathrm{~mm}, \mathrm{SEM})$. Thus, there were narrower 2-DG bands and narrower interband segments of attenuated activity across $\mathrm{V} 2$ cortex at the level of the lunate sulcus relative to posterior and ventral portions of $\mathrm{V} 2$.

In addition to differences in width, differences also were observed in the density of label across individual bands in V2; that is, some of the 2-DG bands were much darker than others. This variation in the size and density of $\mathrm{V} 2$ bands may be related to the patterns of cytochrome oxidase strips that have been described in V2 (e.g., Livingstone and Hubel, 1982, 1984; Humphrey and Hendrickson, 1983; Tootell et al., 1983).

\section{Further comparisons of ${ }^{3} \mathrm{H}$ and ${ }^{14} \mathrm{C}$ images}

The overall patterns of activity labeled by ${ }^{3} \mathrm{H}$ and by ${ }^{14} \mathrm{C}$ in the separate images were similar to one another in both $\mathrm{V} 1$ and $\mathrm{V} 2$; however, there were differences between the 2 labels in the rel-

\footnotetext{
Figure 2. Color images from the same brain section of a portion of dorsolateral striate cortex, V1 (left) and ventral extrastriate area V2 (right) of monkey \#2 showing the ocular dominance columns of V1 and the coincident bands of increased 2-DG uptake in V2 as revealed by the pattern of ${ }^{14} \mathrm{C}$ - and ${ }^{3} \mathrm{H}-2-\mathrm{DG}$ uptake separately (top and middle), and then combined (bottom) following sequential monocular visual stimulation as outlined in the previous figure (see also text). Scale bar (lower right), $1 \mathrm{~mm}$ (for all panels). Left top and left middle, A green image of ${ }^{3} \mathrm{H}-2-\mathrm{DG}$ uptake and a red image ${ }^{14} \mathrm{C}-2-\mathrm{DG}$ uptake from the same tissue section. The ${ }^{14} \mathrm{C}$ image is taken from an $\mathrm{X}$-ray autoradiograph; however, the image of ${ }^{3} \mathrm{H}-2$ DG uptake is produced with a computer by subtracting the ${ }^{14} \mathrm{C}$ label from a combined image of ${ }^{14} \mathrm{C}$ and ${ }^{3} \mathrm{H}$ activity depicted on Ultrofilm. The ocular dominance columns for the left eye, labeled by ${ }^{14} \mathrm{C}$, interdigitate with the ocular dominance columns for the right eye, which are labeled by ${ }^{3} \mathrm{H}$. To illustrate this point, 5 asterisks were placed in identical positions across the dorsolateral surface of V1; note that they mark columns in the ${ }^{14} \mathrm{C}$ image and intercolumn spaces in the ${ }^{3} \mathrm{H}$ image. Left bottom: Interdigitation of the columns labeled by ${ }^{14} \mathrm{C}$ and those labeled by ${ }^{3} \mathrm{H}$ is illustrated by superimposing the red and green images of the 2 labels. Right top and right middle, The green and red images show, respectively, the separate pattern of ${ }^{3} \mathrm{H}$ and ${ }^{14} \mathrm{C}-2-\mathrm{DG}$ uptake across a segment of V2. These images were produced as described above for V1. Several band of increased 2-DG uptake are indicated by asterisks, which were placed in identical positions across the ventral surface of V2. Right bottom, The patterns of ${ }^{3} \mathrm{H}$ and ${ }^{14} \mathrm{C}$ activity across this segment of $\mathrm{V} 2$ are superimposed in this composite image. The coincidence of the band of increased activity labeled by ${ }^{14} \mathrm{C}$ and thosc labcled by ${ }^{3} \mathrm{H}$ is indicated by the patches of yellow. Abbreviations: Cal, internal calcarine sulcus; $I O$, inferior occipital sulcus; $O T$, occipitotemporal sulcus.
} 

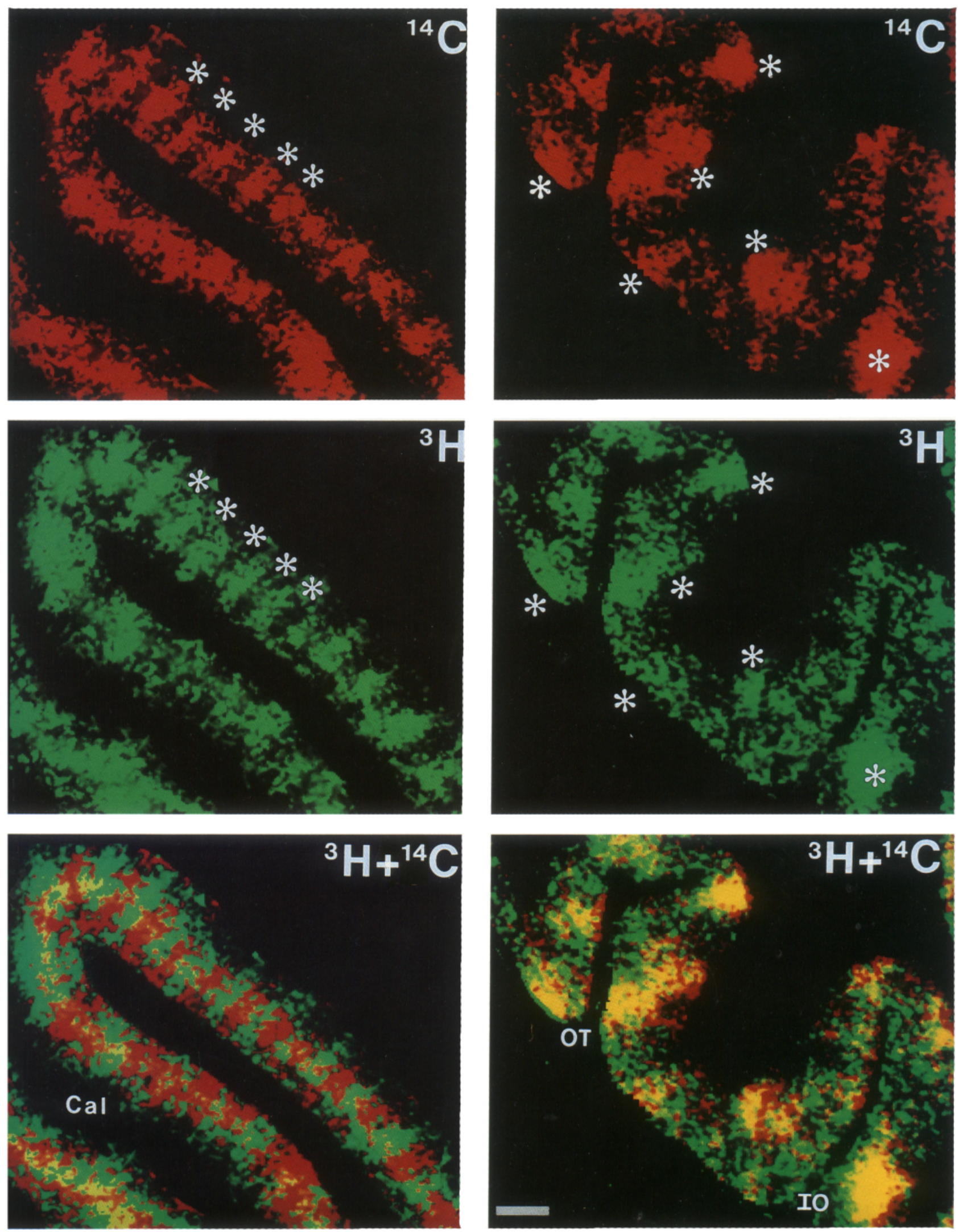

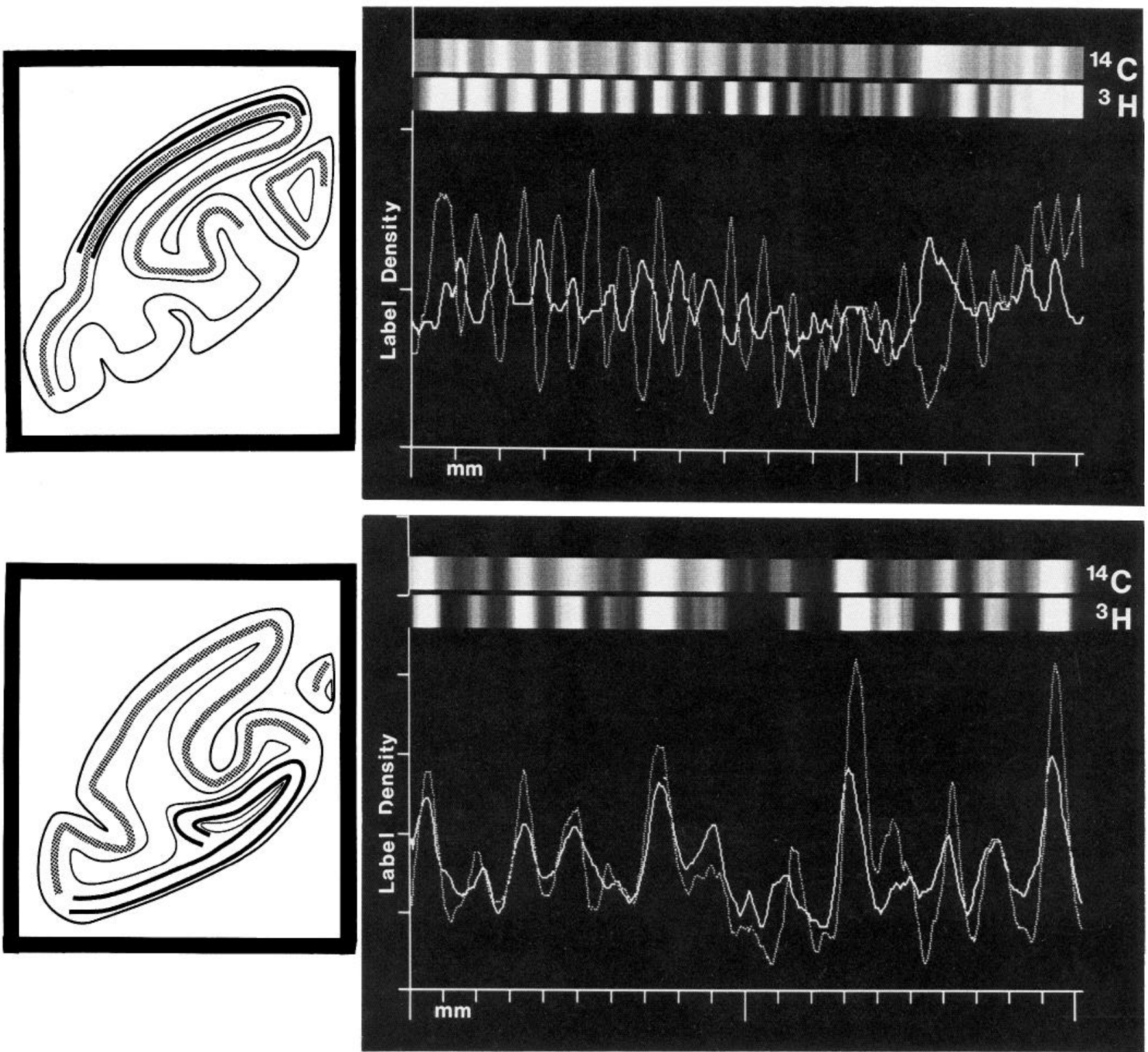

Figure 3. Density graphs and density-strip plots of ${ }^{3} \mathrm{H}$ and ${ }^{14} \mathrm{C}$ activity taken from columnar density curves across a portion of the dorsolateral surface of V1 (top) and across a portion of V2 (bottom) for monkey \#2. In the density-plot strips, the lighter portions represent high activity and the darker portions represent lower activity. Top, Superimposed graphs of ${ }^{14} \mathrm{C}$ activity (solid lines) and ${ }^{3} \mathrm{H}$ activity (dotted lines) across $15 \mathrm{~mm}$ of V1. Density-strip plots of the same data are placed above the graphs using the same abscissa. These data were taken from a contour curve through dorsolateral V1 as indicated in the traced section at left. The gray hatching in the traced section indicates layer IV of V1, and the parallel dark bands indicate the extent of cortex included in the contour curve average. For the graphs and the density-strip plots, activity values of both labels were multiplicatively scaled to the same average value in order to better show the interdigitation of activity. Notice that the peaks of ${ }^{3} \mathrm{H}$ activity are aligned with the troughs of ${ }^{14} \mathrm{C}$ activity and vice versa. Similarly, note that the lighter regions (active columns) in the ${ }^{3} \mathrm{H}$ density-strip are aligned with the darker regions in the ${ }^{14} \mathrm{C}$ strip and vice versa. Bottom, Superimposed graphs of ${ }^{14} \mathrm{C}$ activity (solid lines) and ${ }^{3} \mathrm{H}$ activity (dotted lines) and aligned density-strip plots across $20 \mathrm{~mm}$ of V2. Again, the parallel dark bands in the traced section indicate the extent of cortex included in the contour curve average and the gray hatching indicates layer IV of V1. Activity values of both labels were again scaled to a common average. Note that the peaks of activity for ${ }^{3} \mathrm{H}$ and the peaks for ${ }^{14} \mathrm{C}$ are coincident in the graph, and the ${ }^{14} \mathrm{C}$ and ${ }^{3} \mathrm{H}$ bands are coincident in the density-strip plots.

ative contrast of activity between 2 -DG columns and intercolumn spaces. These differences are most apparent in the graphs of monkey \#2 for the density plots of V1 and V2 (Fig. 3, top and bottom). In both areas, the relative contrast in label density between the peaks and troughs, i.e., the columns and intercolumns spaces, is greater in the ${ }^{3} \mathrm{H}$ graph compared with the ${ }^{14} \mathrm{C}$ graph.
The smaller variation between peaks and troughs in the ${ }^{14} \mathrm{C}$ graph may be partly due to blurring in the ${ }^{14} \mathrm{C}$ autoradiographs produced by the intrinsic scatter of energetic ${ }^{14} \mathrm{C} \beta$-emissions, aggravated by the long film exposure period (necessitated by the low dose of ${ }^{14} \mathrm{C}-2-\mathrm{DG}$ ) and the interposition of the Mylar sheet (to prevent ${ }^{3} \mathrm{H}$ coexposure). However, the inferior resolution of ${ }^{14} \mathrm{C}$ activity relative to ${ }^{3} \mathrm{H}$ activity cannot by itself fully account 

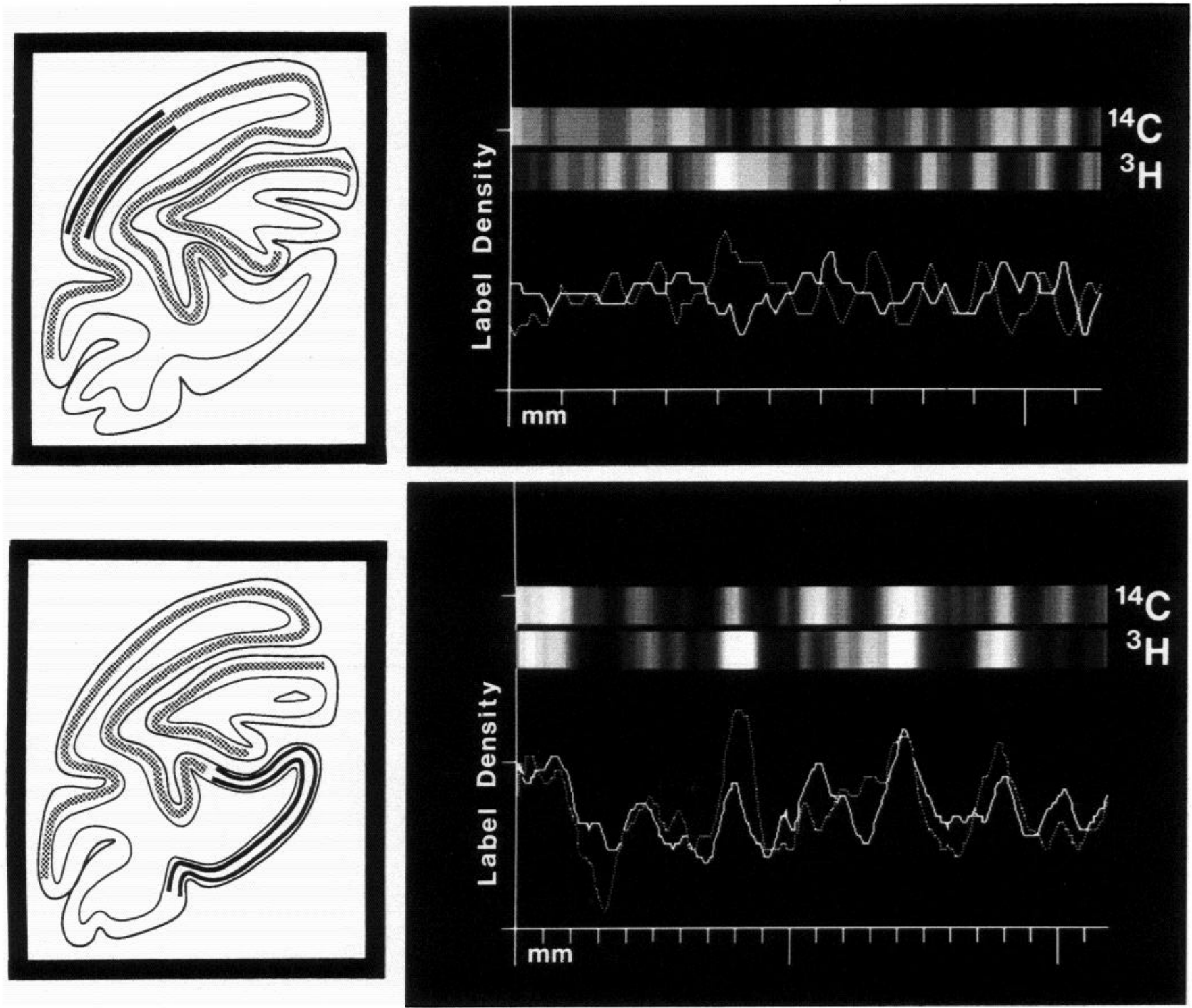

Figure 4. Superimposed density graphs and aligned density-strip plots of ${ }^{3} \mathrm{H}$ and ${ }^{14} \mathrm{C}$ activity taken from columnar density curves across 11 mm of the dorsolateral surface of $\mathrm{V} 1$ (top) and across $21 \mathrm{~mm}$ of $\mathrm{V} 2$ (bottom) for monkey \#1. The lighter portions of the density-plot strips represent high activity, and the darker portions represent lower activity. As in the previous figure, ${ }^{3} \mathrm{H}$ activity (dotted lines) and ${ }^{14} \mathrm{C}$ activity (solid lines) are largely interdigitated in V1 but are largely coincident in V2. The parallel dark bands in the traced sections at left indicate the extent of cortex included in the contour curve average and the gray hatching indicates layer IV throughout V1. Activity values of both labels were multiplicatively scaled to the same average value.

for these interlabel differences in columnar contrast because this resolution factor should apply equally to columns in V1 and V2. Yet, as can be readily seen in Figure 3 (top vs. bottom), the discrepancy in contrast across labels was much more pronounced in area V1 than in V2. To index the contrast of the ${ }^{3} \mathrm{H}$ and ${ }^{14} \mathrm{C}$ density curves, we divided the standard deviation of activity across a columnar density curve by its mean activity. A contrast ratio, the ${ }^{3} \mathrm{H}$ index divided by the ${ }^{14} \mathrm{C}$ index, was calculated for each columnar density curve generated for monkey \#2. In V2 the average ${ }^{3} \mathrm{H} /{ }^{14} \mathrm{C}$ contrast ratio was $1.77( \pm 0.13$, $\mathrm{SEM})$, whereas in $\mathrm{V} 1$ the average contrast ratio was $2.66( \pm 0.12$, $\mathrm{SEM}$ ). This suggests that in $\mathrm{V} 1$ the ${ }^{14} \mathrm{C}$ label was less restricted to one set of ocular dominance columns than was the ${ }^{3} \mathrm{H}$ label. In the Discussion we explore the possibility that leakage of ${ }^{14} \mathrm{C}$ from the set of ocular dominance columns activated in the first experimental session and its subsequent reuptake into the co- lumnar system activated by the second condition could markedly attenuate the contrast between peaks and troughs in the column density curves and, of course, in the images themselves. The bands of V2, however, would be less affected by such leakage and reuptake because the same system of bands appears to have been activated in both conditions. Ways to minimize this leakage problem are discussed as well.

\section{Discussion}

The ${ }^{3} \mathrm{H}$ and ${ }^{14} \mathrm{C}$ autoradiograph images produced in this experiment further demonstrate the utility of the double-label method by showing that it can resolve differences in metabolic activity across 2 conditions at the level of the cortical column in the visual system. In this experiment, ${ }^{3} \mathrm{H}$ - and ${ }^{14} \mathrm{C}-2-\mathrm{DG}$ were used to map the ocular dominance columns of both eyes, and the demonstration of interdigitating ${ }^{3} \mathrm{H}$ - and ${ }^{14} \mathrm{C}$-labeled ocular 

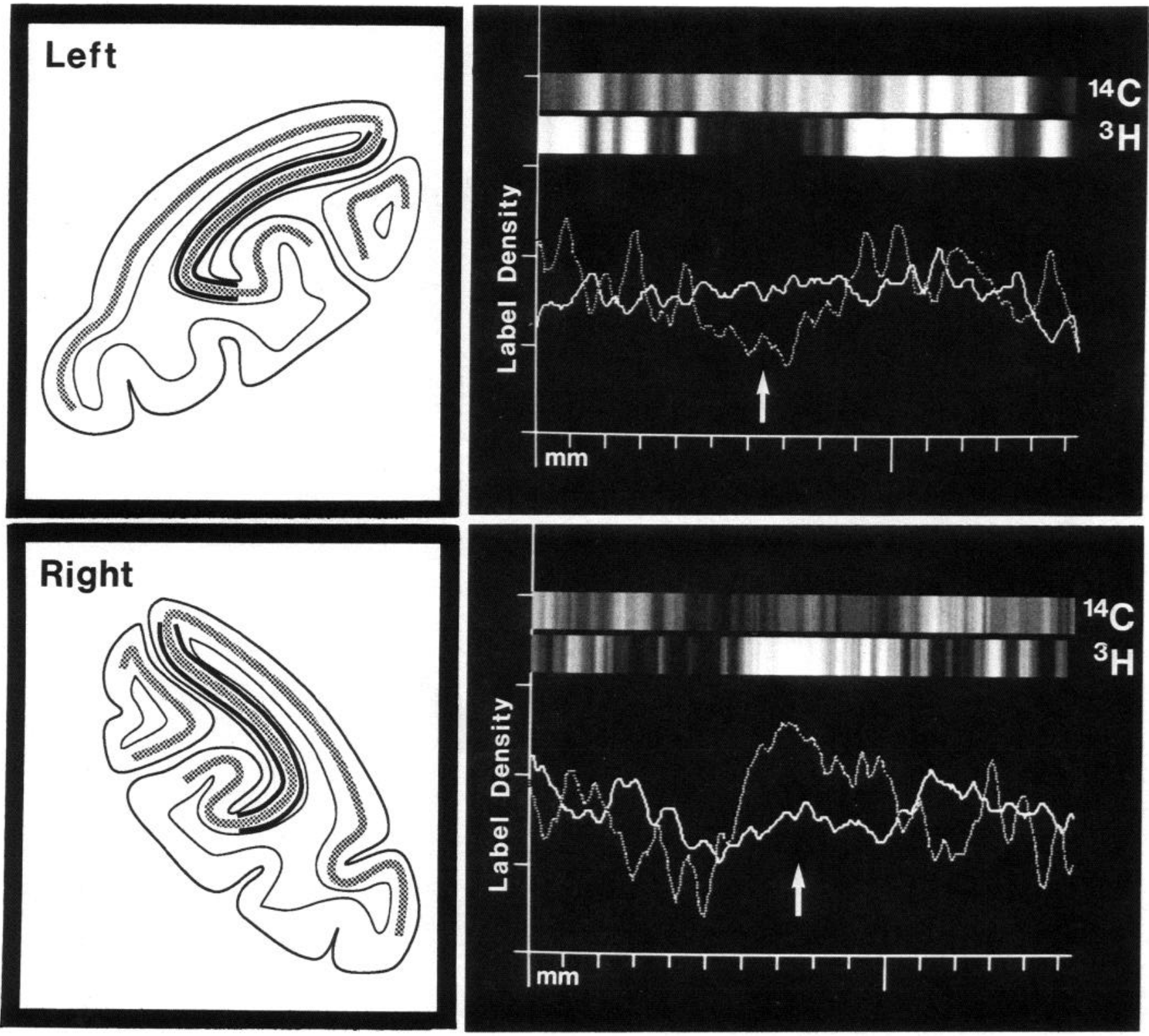

Figure 5. Density graphs and density-strip plots of ${ }^{3} \mathrm{H}$ and ${ }^{14} \mathrm{C}$ activity taken from columnar density curves across the roof of the calcarine sulcus in the left (top) and right (bottom) hemispheres of monkey \#2. As in the the previous figure, the lighter portions of the density-lot strips represent high activity and the darker portions represent lower activity. The solid lines indicate ${ }^{14} \mathrm{C}$ activity and the dotted lines indicate ${ }^{3} \mathrm{H}$ activity. The center of each density graph and density-strip plot shows the optic disk representation (indicated by the arrows), an acolumnar area predominantly activated by the ipsilateral eye. In the left hemisphere (top), the optic disk area is marked by diminished ${ }^{3} \mathrm{H}$ radioactivity as this isotope was administered during visual stimulation of the contralateral eye. Similarly, in the right hemisphere (bottom), the label for the contralateral eye, in this instance ${ }^{14} \mathrm{C}$, is attenuated in the representation of the optic disk. The ocular dominance columns in other regions of the deep calcarine sulcus, i.e., those seen at either side of the optic disk representation, were less regular than the columns of the dorsolateral surface of V1. For both hemispheres, the parallel dark bands in the traced section on the left indicate the extent of cortex included in the contour curve's average and the gray hatching indicates layer IV of V1. Activity values of both labels were always scaled to a common average.

dominance columns in V1 showed that activity for each of the 2 monocular viewing session had been mapped separately. Labeled bands of high activity separated by regions of low activity also were found in V2, but, in contrast to the V1 finding, these V2 bands were coincident for the 2 labels indicative of interocular convergence in V2. Because the double-label 2-DG method can resolve differences in metabolic activity at the columnar level, it is applicable to research questions in which subtle fluctuations of the pattern of metabolic activity may differentiate between behavioral states in experimental animals.

\section{Patterns of metabolic activity in VI}

The autoradiograph images of $\mathrm{V} 1$ provide, to our knowledge, the first demonstration of the system of ocular dominance columns for both eyes in a single subject. These data are entirely consistent with single-label anatomical (e.g., LeVay et al., 1975, 1985) and 2-DG metabolic studies of V1 (e.g., Kennedy et al., 1976; Hendrickson and Wilson, 1979) in showing for each label a pattern of individually alternating columns of high and low metabolic activity and a periodicity of ocular dominance "hy- 
percolumns" of roughly $845 \mu \mathrm{m}$. This pattern of interdigitating ${ }^{3} \mathrm{H}$ and ${ }^{14} \mathrm{C}$ ocular dominance columns was interrupted in the segments of the calcarine sulcus representing the optic disk and monocular crescent where one label dominated. A more subtle irregularity was noted near the representation of the fovea on the dorsolateral surface of $\mathrm{V} 1$; this finding also is consistent with previous metabolic and anatomical tracer studies indicating that ocular dominance columns can be irregular (LeVay et al., 1985) or blurred (Tootell et al., 1988b) at the foveal representation in V1.

We did not obtain perfect negative correlations $(-1.0)$ for the density curves through V1. While this may reflect leakage of the ${ }^{14} \mathrm{C}$ labcl (sce below), overlap between the columnar systems activated by each eye also should be considered. Outside of layer 4C, most cells in V1 can be driven by both eyes (Hubel et al., 1975), and the radial limits of our columnar density curves were set to include laminae III and V. Similarly, the correlations may be affected by the patches of high intrinsic metabolic activity in V1 that would be active in both ocular conditions; high intrinsic metabolio activity in layer 4 as well as in supra- and infragranular layers of V1 in the monkey has been shown using cytochrome oxidase histochemistry (e.g., Horton and Hubel, 1981; Humphrey and Hendrickson, 1983; Livingstone and $\mathrm{Hu}-$ bel, 1984; Tootell et al., 1988a). Future studies combining the double-label 2-DG method and cytochrome oxidase staining should be informative regarding this and other issues.

\section{Patterns of metabolic activity in V2}

In area $\mathrm{V} 2$, the bands of high activity labcled by ${ }^{3} \mathrm{H}$ were largely coincident with the bands of high activity labeled by ${ }^{14} \mathrm{C}$. Thus, in contrast to the ocular dominance columns in V1, metabolism in V2 did not appear to depend on which eye was stimulated. This finding is also consonant with electrophysiological studies: most V2 cells are driven almost equally well by stimulation of either eye alone (Hubel and Wiesel, 1970; Poggio and Fischer, 1977; Zeki, 1978). There are at least 2 explanations for the V2 bands themselves. First, some of these bands may be regions of intrinsically high metabolic activity; the similarity of 2-DG patterns and cytochrome oxidase patterns in V2 has been noted (Humphrey and Hendrickson, 1983; Tootell et al., 1983; Livingstone and Hubel, 1984). Second, some of these bands could reflect specific activation of functional columns in V2 by features of the visual stimulation distinct from its ocularity. For example, we did not vary spatial frequency, depth, or color across the 2 experimental periods, and cells in V2 are often selective for these visual parameters (e.g., Hubel and Wiesel, 1970; Poggio and Fischer, 1977; Hubel and Livingstone, 1985; Shipp and Zeki, 1985; Burkhalter and Van Essen, 1986). Furthermore, cells in V2 with similar receptive field preferences are aggregated in patches or stripes as delineated by cytochrome oxidase staining (DeYeo and Van Essen, 1985; Hubel and Livingstone, 1985; Shipp and Zeki, 1985).

The overall patterning of 2-DG metabolism found in V2 also appears consisted with previous single-label 2-DG studies that have reported discrete patches of increased 2-DG uptake in V2 in the monkey (Livingstone and Hubel, 1982; Tootell et al., 1983; Crawford, 1985), although the bands in our material were more widely spaced and irregular than these reports indicate. However, the banding pattern of 2-DG uptake in V2 varied with the topography of the visual field representation across this cortex: the width of bands and interband segments was larger in ventral portions of $\mathrm{V} 2$ that map the peripheral visual field in comparison with the pattern seen in a portion of V2 at the level of the lunate sulcus that represents more central vision. Therefore, across-study differences in the pattern of 2-DG uptake across V2 may reflect differences in the part of V2 that is selected for study, as well as the plane of section used to evaluate these patterns.

\section{Methodological concerns}

In our previous presentation of this method (Friedman et al., 1987), our emphasis was on extracting the pattern of ${ }^{3} \mathrm{H}$ activity from the contaminated $\left({ }^{14} \mathrm{C}+{ }^{3} \mathrm{H}\right)$ Ultrofilm image, and we derived a subtraction algorithm that provides a veridical image of ${ }^{3} \mathrm{H}$ uptake from X-ray and Ultrofilm autoradiographs. The present demonstration of interdigitating columns in $\mathrm{V} 1$ contrasted with the coincident bands in V2 provides further validation for this subtraction method. One issue of concern, however, is the functional validity of the ${ }^{14} \mathrm{C}$ images. The attenuated contrast of the ${ }^{14} \mathrm{C}$ columnar density curves relative to the ${ }^{3} \mathrm{H}$ columnar density curves indicates that a significant fraction of the ${ }^{14} \mathrm{C}$ label reflected the second experimental condition, meaning that some ${ }^{14} \mathrm{C}$-labeled 2-DG was available in plasma during that condition. This unwanted 2-DG can come from 2 nonexclusive sources: First, the initial experimental condition may be of insufficient duration for complete plasma clearance of the first dose of 2-DG; therefore, it may still be available when the second experimental condition commences. Conversely, the total duration of the experiment may permit some of the ${ }^{14} \mathrm{C}-2$ DG incorporated during the first condition to dephosphorylate, and thus become available again for uptake during the second experimental condition. In either case, not only would some of the first label be lost from the system of ocular dominance columns activated by the first condition, but moreover, it would be incorporated into the system of columns activated by the second condition. Both of these circumstances would serve to reduce the contrast of the ${ }^{14} \mathrm{C}$ columnar density curves.

Therefore, in selecting temporal intervals for double-label experiments, one must limit the availability of the first label during the second condition by maximizing the plasma clearance of the first label during the first condition while minimizing its reavailability via dephosphorylation during the second condition. Moreover, the second experimental interval must be long enough to allow sufficient uptake of the second label in the second condition but still short enough to reduce, as much as possible, the reavailability of the first labeled dose of 2-DG by dephosphorylation. An inappropriate choice of intervals, such as $\mathbf{4 5} \mathrm{min}$ for each condition, may make the double-label idea appear flawed (Webster et al., 1983; McEachron et al., 1987, 1988), although differential metabolic uptake qualitatively reflecting the difference in experimental conditions is still obtained with these intervals (e.g., John et al., 1986; Redies et al., 1987). However, the diminished contrast in our ${ }^{14} \mathrm{C}$ images indicates that the $30 \mathrm{~min}$ per condition protocol we chose is probably not optimal either. One way to further attenuate this problem may be to limit the entire experimental period to only $45 \mathrm{~min}$, with $35 \mathrm{~min}$ for the first test period and only $10 \mathrm{~min}$ for the second. Dephosphorylation of 2-DG-6-phosphate (DG-6-P) is negligible for $45 \mathrm{~min}$ following an injection of 2-DG (Sokoloff et al., 1977; Deuel et al., 1985; Nelson et al., 1985, 1986a, b; Deuel, 1986), and DG-6-P concentrations in brain are very close to their maximal values after 35 min (e.g., Figs. 1 and 2 of Nelson et al., 1986a). Moreover, because the duration of the second condition would be reduced by a factor of 3 , the proportion of the first 
label corrupted by the second condition may become negligible. Finally, although an increase in the 2-DG dose may be required, the uptake pattern of the second label should remain faithful to the metabolism accompanying the second condition because over $50 \%$ of a bolus injection of $2-\mathrm{DG}$ is incorporated into DG6-P within 10 min (again Figs. 1 and 2 of Nelson et al., 1986a), and the remaining label should be flushed by the perfusion that immediately follows. Our results thus far (Friedman et al., 1989) indicate that such changes in the parameters of the double-label 2-DG protocol can improve the separation of distinct patterns of brain metabolism by the 2 types of label. However, even with the parameters used, the demonstration of interdigitating left and right eye ocular dominance columns in the present study shows that the double-label 2-DG technique can already dissociate functional activity underlying 2 behavioral states at the level of the cortical column.

\section{References}

Altenau, L. L., and B. W, Agranoff (1978) A sequential double-label 2-deoxyglucose method for measuring regional cerebral metabolism. Brain Res. 153: 375-381.

Bruce, C. J., H. R. Friedman, and P. S. Goldman-Rakic (1985) Demonstration of interdigitating functional columns in rhesus monkey using a double-label 2-DG subtraction technique. Soc. Neurosci. Abstr. 11: 1089.

Burkhalter, A., and D. C. Van Essen (1986) Processing of color, form and disparity information in visual areas VP and V2 of ventral extrastriate cortex in the macaque monkey. J. Neurosci. 6: 2327-2361.

Collins, R. C. (1978) Use of cortical circuits during focal penicillin seizures: An autoradiographic study with $\left[{ }^{14} \mathrm{C}\right]$ deoxyglucose. Brain Res. 150: 487-501.

Crawford, M. L. J. (1985) Stimulus-specific columns in monkey visual cortex as revealed by the ${ }^{14} \mathrm{C}$-2-deoxyglucose method. In Cerebral Cortex, A. Peters and E. G. Jones, eds., pp. 331-349, Plenum, New York.

Deuel, R. K. (1986) Measurement of brain deoxyglucose mctabolism by NMR. Science 232: 777.

Deuel, R. K., G. M. Yue, W. R. Sherman, D. J. Schnickner, and J. H. Ackermann (1985) Monitoring the time course of cerebral deoxyglucose metabolism by ${ }^{32} \mathrm{P}$ nuclear magnetic resonance. Science 228 : 1329-1331.

DeYeo, E. A., and D. C. Van Essen (1985) Segregation of efferent connections and receptive field properties in visual area V2 of the macaque. Nature 317: 58-61.

Friedman, H. R., and P. S. Goldman-Rakic (1988) Activation of the hippocampus and dentate gyrus by working-memory: A 2-deoxyglucose study of behaving rhesus monkeys. J. Neurosci. 8: 4693-4706.

Friedman, H. R., C. J. Bruce, and P. S. Goldman-Rakic (1987) A sequential double-label ${ }^{14} \mathrm{C}$ - and ${ }^{3} \mathrm{H}-2$-DG technique: Validation by double-dissociation of functional states. Exp. Brain Res. 66: 543-554.

Friedman, H. R., C. J. Bruce, and P. S. Goldman-Rakic (1989) Temporal parameters for optimal separation of experimental conditions in the double-label 2DG method. Soc. Neurosci. Abstr., 15 (in press).

Gatass, R., C. J. Gross, and J. H. Sandell (1981) Visual topography of V2 in the macaque. J. Comp. Neurol. 201: 579-539.

Goldman-Rakic, P.S. (1984) Modular organization of prefrontal cortex. Trends Neurosci. 7: 419-429.

Hendrickson, A. E., and J. R. Wilson (1979) A difference in $\left[{ }^{4} \mathrm{C}\right]$ deoxygluose autoradiographic patterns in striate cortex between Macaca and Saimiri monkeys following monocular stimulation. Brain Res. 170: 353-358.

Horton, J. C., and D. H. Hubel (1981) Regular patchy distribution of cytochrome oxidase staining in primary visual cortex of macaque monkey. Nature 292: 762-764.

Hubel, D. H., and T. N. Wiesel (1970) Cells sensitive to binocular depth in area 18 of the macaque monkey cortex. Nature 225:41-43.

Hubel, D. H., and M. S. Livingstone (1985) Complex-unoriented cells in a subregion of primate area 18. Nature $315: 325-327$.

Hubel, D. H., T. N. Wiesel, and S. LeVay (1975) Functional architecture of area 17 in normal and monocularly deprived macaque monkeys. Cold Spring Harbor Symp. Quant. Biol. 40: 581-589.
Humphrey, A. L., and A. E. Hendrickson (1983) Background and stimulus-induced patterns of high metabolic activity in the visual cortex (area 17) of the squirrel and macaque monkey. J. Neurosci. 3: 345-358.

John, E. R., Y. Tang, A. B. Brill, R. Young, and K. Ono (1986) Doublelabeled metabolic maps of memory. Science 233: 1167-1175.

Kennedy, C., M. H. DesRosiers, O. Sakurada, M. Shinohara, M. Reivich, J. W. Jehle, and L. Sokoloff (1976) Metabolic mapping of the primary visual system of the monkey by means of the autoradiographic $\left[{ }^{14} \mathrm{C}\right]$ deoxyglucose technique. Proc. Natl. Acad. Sci. USA 73: $4230-4234$.

Kronenberg, L. H. (1979) Radioautography of multiple isotopes using color negative films. Anal. Biochem. 93: 189-195.

LeVay, S., D. H. Hubel, and T. N. Wiesel (1975) The pattern of ocular dominance columns in macaque visual cortex revealed by a reduced silver stain. J. Comp. Neurol. 159: 559-576.

LeVay, S., M. Connolly, J. Houde, and D. C. Van Essen (1985) The complete pattern of ocular dominance stripes in the striate cortex and visual field of the macaque monkey. J. Neurosci. 5: 486-501.

Livingstone, M. S., and D. H. Hubel (1981) Effects of sleep and arousal on the processing of visual information in the cat. Nature 291: 554561 .

Livingstone, M. S., and D. H. Hubel (1982) Thalamic inputs to cytochrome oxidase-rich regions in monkey visual cortex. Proc. Natl. Acad. Sci. USA 79: 6098-6101.

Livingstone, M. S., and D. H. Hubel (1984) Anatomy and physiology of a color system in the primate visual cortex. J. Neurosci. 4: 309356.

McCasland, J. S., and T. A. Woolsey (1988) New high resolution 2-deoxyglucose method featuring double-labeling and automated data collection. J. Comp. Neurol. 278: 555-569.

McEachron, D. L., C. R. Gallistel, and P. Hand (1987) Letter. Science 238: 1587

McEachron, D. L., P. Hand, and C. R. Gallistel (1988) Sequential double-labeling with 2-deoxyglucose (2-DG): A test of the primary assumption. Soc. Neurosci. Abstr. 14: 918.

Mountcastle, V. B. (1978) An organizing principle for cerebral function: The unit module and the distributed system. In The Neurosciences, Fourth Study Program, F. O. Schmitt and F. G. Worden, eds., pp. 21-42, MIT Press, Cambridge, MA

Nelson, T., G. Lucignani, S. Atlas, A. Crane, G. A. Dienel, and L. Sokoloff (1985) Reexamination of glucose-6-phosphatase activity in the brain in vivo: No evidence for a futile cycle. Science 229:6062 .

Nelson, T., G. Lucignani, J. Goochee, A. Crane, G. A. Dienel, and L. Sokoloff (1986a) Invalidity of criticisms of the deoxyglucose method based on alleged glucose-6-phosphatase activity in brain. Neurochemistry 46: 905-919.

Nelson, T., G. Lucignani, and L. Sokoloff (1986b) Measurement of brain deoxyglucose metabolism by NMR. Science 232: 776-777.

Newman, W. M., and R. F. Sproull (1973) Principles of Interactive Computer Graphics, pp. 320-324, McGraw-Hill, New York.

Poggio, G. F., and B. Fischer (1977) Binocular interaction and depth sensitivity in striate and prestriate cortex of the behaving rhesus monkey. J. Neurophysiol. 40: 1392-1405.

Redies, C., M. Diksic, A. C. Evans, A. Gjedde, and Y. L. Yamamoto (1987) Double-label autoradiographic deoxyglucose method for sequential measurement of regional cerebral glucose utilization. Neuroscience 22: $601-619$.

Shipp, S., and S. Zeki (1985) Segregation of pathways leading from area V2 to areas V4 and V5 of the macaque monkey visual cortex. Nature 315: 322-325.

Sokoloff, L., M. Reivich, C. Kennedy, M. H. DesRosiers, C. S. Patlak, K. D. Pettigrew, O. Sakurada, and M. Shinohara (1977) The $\left[{ }^{14} \mathrm{C}\right]$ deoxyglucose method for the measurement of local cerebral glucose utilization: Theory, procedure, and normal values in the conscious and anesthetized albino rat. J. Neurochem. 28: 897-916.

Szentagothai, J. (1975) The module concept in cerebral cortex architecture. Brain Res. 95: 475-496.

Tootell, R. B. H., M. S. Silverman, R. L. De Valois, and G. H. Jacobs (1983) Functional organization of the second cortical visual area in primates. Science 220:737-739.

Tootell, R. B. H., S. Hamilton, M. S. Silverman, and E. Switkes (1988a) Functional anatomy of macaque striate cortex. I. Ocular dominance, binocular interactions, and baseline conditions. J. Neurosci. 8: 15001530. 
Tootell, R. B. H., E. Switkes, M. S. Silverman, and S. Hamilton (1988b) Functional anatomy of macaque striate cortex. II. Retinotopic organization. J. Neurosci. 8: 1531-1568.

Tootell, R. B. H., R. T. Born, and S. L. Hamilton (1988c) Studies of primate visual cortex using a double-label DG technique and color autoradiography. Soc. Neurosci. Abstr. 14: 897.
Webster, W. R., J. Serviere, R. Martin, and E. Hartley (1983) Tonotopic bands produced by tones commenced long after 2-deoxyglucose injection. Neurosci. Lett. 40: 281-286.

Zeki, S. M. (1978) Uniformity and diversity of structure and function in rhesus monkey prestriate visual cortex. J. Physiol. (Lond.) 277: 273-290. 